\title{
Correction
}

\section{Correction to: Backtracking Search Optimization: A Novel Global Optimization Algorithm for the Inversion of Gravity Anomalies}

\author{
Yunus Levent Ekinci, ${ }^{1}$ (D) ÇaĞLayan Balkaya, ${ }^{2}$ (i) and Gökhan Göktürkler ${ }^{3}$ (i)
}

Correction to: Pure Appl. Geophys. (2021).

https://doi.org/10.1007/s00024-021-02855-3

The original version of this paper was inadvertently published with incorrect equation numbers in the first sentence of the Appendix.

The correct sentence is:

The definitions of the terms in Eqs. 7 and 8 are given as follows (Chakravarthi \& Sundararajan, 2007)

The original article has been corrected. We apologise for any inconvenience caused to our readers.

(Published online October 28, 2021)

The original article can be found online at https://doi.org/10.1007/ s00024-021-02855-3.

\footnotetext{
1 Department of Art History, Bitlis Eren University, Bitlis, Turkey. E-mail: ylekinci@beu.edu.tr

2 Department of Geophysical Engineering, Süleyman Demirel University, Isparta, Turkey.

3 Department of Geophysical Engineering, Dokuz Eylül University, İzmir, Turkey.
} 